Original article

\title{
How does the replacement of rice flour with flours of higher nutritional quality impact the texture and sensory profile and acceptance of gluten-free chocolate cakes?
}

\author{
Lucas de Souza Nespeca, ${ }^{1}$ Hellen Fernanda da Silva Paulino, ${ }^{1}$ Tamires Barlati Vieira da Silva, ${ }^{2}$ \\ Evandro Bona, ${ }^{2}$ (D) Fernanda Vitória Leimann,,3 (D) Leila Larisa Medeiros Marques, ${ }^{1}$ (iD \\ Flávia Aparecida Reitz Cardoso, ${ }^{4}$ (iD Adriana Aparecida Droval ${ }^{1}$ (iD \& Renata Hernandez Barros Fuchs ${ }^{2 *}$ \\ 1 Department of Food Engineering, Federal University of Technology - Paraná (UTFPR), Campo Mourão, Paraná 87301-005, Brazil \\ 2 Post-Graduation Program of Food Technology (PPGTA), Federal University of Technology - Paraná (UTFPR), Campo Mourão, Paraná \\ 87301-005, Brazil \\ 3 Centro de Investigação de Montanha (CIMO), Instituto Politécnico de Bragança, Campus Santa Apolônia, Bragança 5300-253, Portugal \\ 4 Post-Graduation Program of in Technological Innovations (PPGIT), Federal University of Technology - Paraná, Campo Mourão, Paraná \\ 87301-005, Brazil
}

(Received 26 August 2020; Accepted in revised form 28 September 2020)

Summary Gluten-free bakery products usually use rice flour as substitute for wheat flour. This paper aims to evaluate whether and how the substitution of rice flour for sorghum and teff flour changes the overall acceptance, texture and sensory profile of gluten-free chocolate cakes. An experimental design composed of three factors (rice, sorghum and teff flours) was developed, and formulations were analysed by acceptance test and fibre content. Four formulations were submitted to sensory descriptive analysis. The formulations did not show significant differences in the overall acceptance although the sensory profile has changed. The texture was affected by the type of flour, being the optimised formulation the softer among the samples. From these data, it can be concluded that it is possible to replace rice flour with sorghum and teff flour in chocolate cake formulations, since the change in the sensory profile did not affect the acceptance of the products.

Keywords Celiac disease, flash profile, gluten-free cakes, sorghum (Sorghum bicolor (L.) Moench), teff (Eragrostis tef).

\section{Introduction}

Celiac disease is defined as an autoimmune disorder that impairs the gastrointestinal system and affects about $1 \%$ of the world's population. The disease has many clinical manifestations, ranging from severe malabsorption to minimally symptomatic or non-symptomatic presentations. Therefore, the only treatment for celiac disease is the definitive exclusion of gluten from the diet (Lebwohl et al., 2018).

Gluten is a protein present in most cereals such as wheat, barley and rye. The differences among the types of grains are based on the proportion of proteins present in them, such as glutenins, which provide elasticity and cohesion to batter, and gliadins, responsible for fluidity, extensibility and expansion (Balakireva \& Zamyatnin, 2016), which are very relevant properties for baking. However, some cereals like rice, sorghum

*Correspondent. E-mail: renata@utfpr.edu.br and teff (Rosell et al., 2014), pseudocereals such as amaranth, quinoa, and buckwheat (Krupa-Kozak et al., 2011; Torbica et al., 2012; Costantini et al., 2014; Giménez-Bastida et al., 2015; Turkut et al., 2016) and seeds such as linseed and chia have none or little of these gluten-forming proteins (Steffolani et al., 2014; Korus et al., 2015).

The low global quality of gluten-free products and the growing number of patients diagnosed with celiac disease have led to the investigation of new ingredients and formulations to obtain gluten-free products as similar as possible to wheat-based products like breads (Marti et al., 2017; Viell et al., 2020), cookies (Torbica et al., 2012; Sakač et al., 2015; da Silva \& Conti-Silva, 2018) and cakes (Marston et al., 2016; Gao et al., 2018; Salehi, 2019). Rice flour (Oryza sativa L.) is the main ingredient in gluten-free bakery products, since it has a neutral taste and odour, is affordable and easy to find. However, like the rice grain, its flour has a 
low nutritional value, consisting basically of starch and smaller amounts of proteins, lipids, fibres and ashes (Torbica et al., 2012). Thus, Capriles \& Arêas (2014) suggest the use of alternative ingredients to improve the nutritional value and diversify the glutenfree baked goods. Sorghum (Sorghum bicolor Moench) and teff (Eragrostis tef) cereals are great alternatives for this purpose. Sorghum is a staple food for more than half a billion people in at least thirty countries (FAO, 2012). It brings health benefits due to the presence of bioactive compounds such as fibres and phenolic compounds, which contribute to the proper functioning of the human organism (McCann et al., $2015)$. Teff (E. tef) is also a gluten-free grain with high nutritional value. It is a cereal of Ethiopian origin rich in carbohydrates and fibres in addition to having in its composition more zinc, iron and calcium than other grains such as wheat and rice (Campo et al., 2016). Some studies have evaluated the use of teff in glutenfree foods or as a partial substitute for wheat. However, some of such studies only reported the impact of teff utilisation on the texture and nutritional properties of products (Marti et al., 2017; Zhu, 2018).

A product that has excellent chemical, physical, nutritional, or microbiological characteristics is worthless to the consumer, if the sensory characteristic of this product does not fulfil the needs and desires of those who will consume it. The quality of a food implies, among other factors, consumer satisfaction and it is up to him to define the quality parameters of the product (Vad Andersen \& Hyldig, 2015; Andersen et al., 2019). Descriptive sensory analysis provides the mapping of similarities and differences between products and helps in determining the attributes that are important for acceptance. The results allow to relate a specific ingredient, with specific changes in the sensory attributes of a product (Stone \& Sidel, 2004).

Given the facts exposed, the objective of this research was to optimise a gluten-free chocolate cake formulation and to evaluate the changes promoted in the texture, and sensory profile and acceptance of these cakes when replacing rice flour with sorghum and teff flours.

\section{Material and methods}

\section{Ingredients}

The chocolate cakes were made with whole-grain flours of brown sorghum (Farovitta ${ }^{\circledR}$ ) and red teff $\left(\right.$ Giroil $\left.^{\circledR}\right)$, and refined rice flour $\left(\right.$ Terra Verde $\left.{ }^{\circledR}\right)$ flour. The remaining ingredients used in the formulations were obtained from the local market of Campo Mourão, Paraná, Brazil. Reagents by analytical standard were supplied by Sigma-Aldrich (St Louis, MI, USA).

\section{Experimental design}

The experimental design was based on a gluten-free chocolate cake formulation made with rice flour (F1). This formulation was composed of milk with $3.0 \%$ fat $(40.24 \%)$, sugar $(20.12 \%)$, rice flour $(11.78 \%)$, soybean oil $(7.80 \%)$, cocoa powder $(7.56 \%)$, eggs $(6.10 \%)$, potato starch $(3.94 \%)$, cassava starch $(1.96 \%)$, baking powder $(0.18 \%)$, xanthan gum $(0.12 \%)$, sodium bicarbonate $(0.12 \%)$ and salt $(0.06 \%)$. F1 can be considered as a standard formulation, since it is composed only of rice flour, basic ingredient of most gluten-free bakery products.

From this basic formulation, a mixture planning was developed to make partial and total substitutions of the rice flour for sorghum and teff flour. The experimental design was the Simplex Centroid $\left(2^{3}-1\right)$ composed of three factors (rice, sorghum and teff flours) and repetition at the central point (Cornell, 2011), as shown in Table 1.

For the fibre quantity response variable, a linear model was fitted (eqn (1)) using the fibre content of each flour. For the overall acceptance variable, a special cubic model was fitted (eqn 2). Statistical analyses were performed using software Statistica 12.1 (StatSoft, Inc., Tulsa, OK, USA).

$$
\begin{aligned}
& y=b_{1} x_{1}+b_{2} x_{2}+b_{3} x_{3} \\
& y=b_{1} x_{1}+b_{2} x_{2}+b_{3} x_{3}+b_{2} x_{2}+b_{12} x_{1} x_{2}+b_{13} x_{1} x_{3} \\
& +b_{23} x_{2} x_{3}+b_{123} x_{1} x_{2} x_{3}
\end{aligned}
$$

The variables $x_{1}, x_{2}$ and $x_{3}$ correspond, respectively, to rice, sorghum and teff flour, substituted in Table 1 by $\mathrm{R}, \mathrm{S}$ and $\mathrm{T}$.

\section{Sample production}

The eggs were homogenised in a planetary mixer SX84 (Arno, São Paulo, Brazil) at high speed (11 $303 \mathrm{~g})$ for 3 min. Milk and soybean oil were added and homogenised for $5 \mathrm{~min}$. Next, the dry ingredients (except the baking powder) were added and mixed for $3 \mathrm{~min}$. Then, the baking powder was added and incorporated into the batter, which was transferred to aluminium pans $(22 \times 10 \mathrm{~cm})$ and baked $\left(180{ }^{\circ} \mathrm{C} / 33 \mathrm{~min}\right)$. Each pan was filled with $450 \mathrm{~g}$ of dough. After being removed from the oven, the cakes remained at room temperature $\left(25^{\circ} \mathrm{C}\right)$ until completely cool and were packed in polyethylene bags until the time of the other analysis.

\section{Microbiological analysis}

The samples were analysed for fecal coliforms and counts of total coliforms and Salmonella spp in $25 \mathrm{~g}$ using the BAX system method from the U.S. Food 


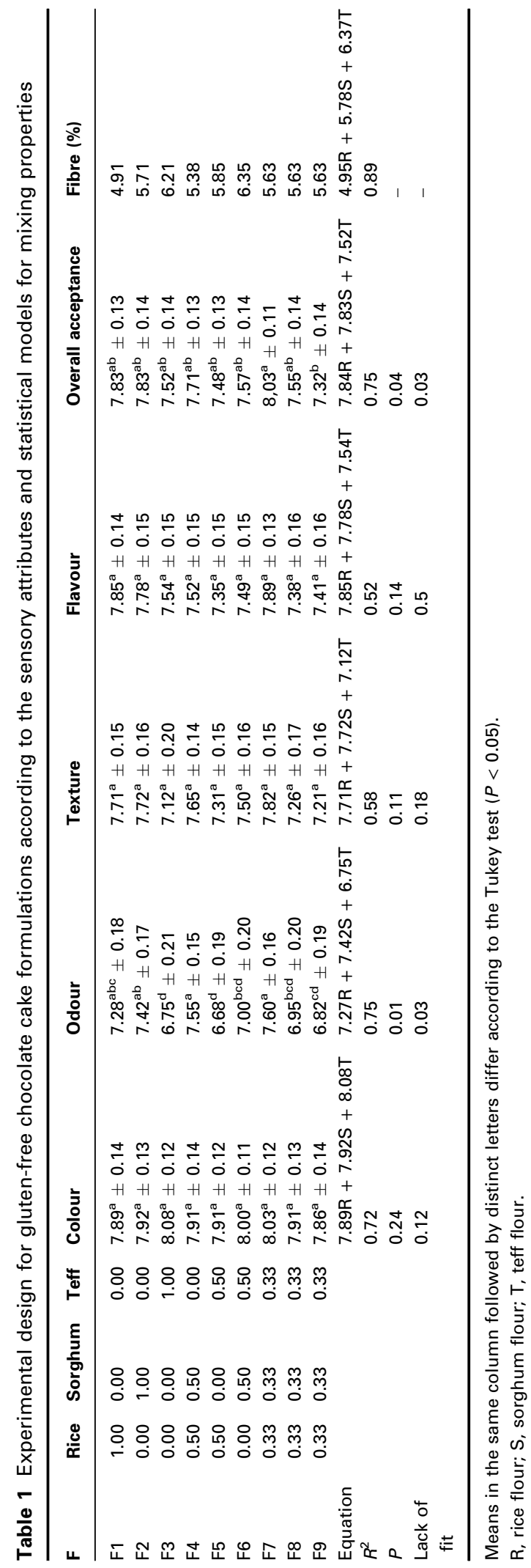

and Drug Administration's Bacteriological Analytical Manual (Feng et al., 2002; Andrews et al., 2007). These analyses are those established by Brazilian legislation (ANVISA, 2001).

\section{Acceptance test}

All the cake formulations were submitted to an acceptance test, evaluating the attributes of overall acceptance, colour, flavour, aroma and texture using a 9-point Hedonic Scale (9-liked extremely; 1-disliked extremely) (Stone \& Sidel, 2004). The tests were applied on three consecutive days in the university's sensory analysis laboratory, with 100 untrained assessors, and all the panellists participated in the 3 days and evaluated all samples. Each assessor was given a pre-screening form to obtain information about age, gender, education completed, frequency of cake consumption, and potential food allergies. Assessors signed an informed consent form to notify them about the purpose and guidelines of the study.

In each sensory analysis session, assessors received three samples, one of which was the repetition of the centre point (33.3\% of each flour type, F7, F8 and F9) and two other samples chosen randomly from the six formulations that make up the experiment $(\mathrm{F} 1, \mathrm{~F} 2, \mathrm{~F} 3$, F4, F5 and F6). Cake samples cut into cubes $\left(2.5 \mathrm{~cm}^{2}\right)$ were served in plates coded with three random digits, in monadic and random order. Samples were always served to assessors $18 \mathrm{~h}$ after production. This time was standardised in all sensory analysis sessions to avoid differences between samples due to changes that could occur in the cakes due to the storage time.

\section{Evaluation of fibre content}

Fibre content of each cake formulation was calculated indirectly, using the fibre content of each raw material provided by the Food Composition Database of the United States Department of Agriculture (USDA, 2015). Fibre contents of the rice, sorghum and teff flours, and the data were based on laboratory analyses (method 991.43) (AOAC, 2005). From these values and the amount of each ingredient present in each formulation, the fibre content of products was calculated.

\section{Formulation optimisation}

After the statistical evaluation of the proposed models, the equations were combined to find the optimum proportion of the rice, teff and sorghum flours using the desirability function (Barros Neto et al., 2010). This approach involves transforming each estimated response variable $y_{i}$ into a desirable value $d_{i}$, where $0 \leq d_{i} \leq 1$. As in the optimised formulation the objective was to use $y_{i}$ as a maximum value, both for 
the fibre and for the global impression, eqn (3) was used.

$$
d_{i}\left(y_{i}(x)\right)=\left[\begin{array}{c}
1 \text { se } y_{i}(x)<L_{i} \\
{\left[\frac{U_{i}-y_{i}(x)}{U_{i}-L_{i}}\right]^{t}} \\
0 \text { se } y_{i}(x)>U_{i}
\end{array}\right]
$$

The individual desirability values $\left(d_{i}\right)$ should then be combined to form the general desirability $(D)$, given by eqn (4).

$$
D=\sqrt[m]{d_{1} d_{2} d_{3} \ldots d_{m}}
$$

with the formulation optimisation process, only four formulations were submitted to the other evaluations proposed in this research: F1 (rice), F2 (sorghum), F3 (teff) and FO (optimised formulation), according to Figure S1.

\section{Flash profile}

Four cake formulations were submitted to sensory descriptions by the Flash Profile method (Dairou \& Sieffermann, 2002), F1, F2, F3 and FO (optimised formulation), which presents the highest overall acceptance and fibre content.

The assessors (12) were selected in compliance with ISO Standard 8586:2012 (ISO, 2012). Then the survey of descriptive attributes was performed, in which assessors tasted the cakes regarding similarities and differences in appearance, aroma, flavour and texture. Each assessor was assisted in developing the descriptive terms, recording and describing them. These descriptive terms were used to elaborate the personalised sensory evaluation form. Samples $\left(2.5 \mathrm{~cm}^{2}\right)$ were presented to the assessors, who were asked to taste and rank them in ascending order, according to the intensity of each attribute. The analyses were performed in triplicate on three alternating days. The results for each assessor were plotted in an array (attributes in the columns and samples in the lines). The data analysis was performed using software MATLAB $\mathrm{R} 2008 \mathrm{~b}$ and the ComDim technique, according to the algorithm proposed by Qannari et al. (2001) and described in detail by Jouan-Rimbaud Bouveresse et al. (2011). The application of this method to this type of analysis was described by Fuchs et al. (2018).

The Ethics Committee of the Federal University of Technology - Paraná approved all sensory evaluations (acceptance test and Flash Profile) under protocol number 88116618.2.0000.5547.

\section{Texture profile analysis (TPA)}

Cakes, without the crust, were cut into cylindrical pieces with diameter of $36 \mathrm{~mm}$ using a stainless-steel cutter. Samples were subjected to a double cycle of compression in a TA-TX/Express Enhanced Texture Analyzer (Stable Micro Systems, UK). For that, a cylindrical $\mathrm{P} / 36 \mathrm{R}$ probe (36 $\mathrm{mm}$ diameter) compressed $30 \%$ of the original cake height at a speed of $2 \mathrm{~mm} \mathrm{~s}^{-1}$. Seven samples of each treatment were evaluated.

The parameters evaluated were hardness, springiness, chewiness, cohesiveness and resilience (Moscatto et al., 2004). The results determined for each parameter were obtained directly from the software associated with the texture analyzer (Expression PC), and such data were analysed using the ANOVA and Tukey test $(P<0.05)$.

\section{Results and Discussion}

\section{Acceptance test and fibre content}

All formulations presented Coliforms values below the limits established by Brazilian legislation RDC $\mathrm{n}^{\circ} .12$ (ANVISA, 2001), besides the absence of Salmonella spp in $25 \mathrm{~g}$ samples, showing that the cakes are suitable for human consumption.

A total of 100 assessors participated in the acceptability study including fifty-nine females and forty-one males. The age of assessors ranged from 18 to 44 years with $65 \%$ of assessors in the eighteen to twenty-five age group. For cake consumption, $61 \%$ assessors claimed to eat cake at least once a month, while $39 \%$ consumed cake at least once every 2 weeks. The results demonstrated that $60 \%$ of respondents claimed they may purchase gluten-free products, while $15 \%$ claimed they would buy and $25 \%$ they would not buy glutenfree products. Table 1 presents the values obtained from the analysis of variance as a function of sensory attributes of each formulation.

The cake samples did not differ significantly for colour, texture and flavour attributes, but there are differences in aroma and overall acceptance attributes. The aroma score varied from 6.68 to 7.60 . The values found for the acceptance of odour of cakes containing sorghum in this study were higher than those found by (Marston et al., 2016), which revolved around 6.2. Formulations F4 and F7 had the highest acceptance regarding this attribute, while formulation F5 showed the lowest approval. Thus, the best acceptance concerning the aroma is associated with the presence of sorghum flour in the formulations, with rice and teff flour making the aroma of the formulations less acceptable. This positive impact of sorghum on the odour of cakes was also verified by (Marston et al., 2016) as well as the negative influence of teff flour on this attribute was observed by (Mohammed et al., 2009) who evaluated the replacement of wheat flour by teff flour in breads. 
Regarding the overall acceptance, there was a variation from 7.32 to 8.03. Formulations F7 and F9, despite being repetitions of the central point, showed a significant difference. F7 presented the most expressive overall acceptance (8.03), while F9 received the lowest (7.32). This may be because they were analysed on different days and, in sensory analysis, the measuring instrument is the human sensory perception, which may vary individually and undergoes constant modifications. Figure 1 presents the overall acceptance that the 100 assessors reported in the sensory analysis. The percentage of those who liked the product was high for all formulations proposed, with F7 and F9 being the $100 \%$ grades comprised between 6 and 9 on the hedonic scale. The F3 formulation showed the highest rejection $(3.5 \%)$ and the neutrality $(4.5 \%)$.

The fibre content of each formulation ranged from $4.91 \%(\mathrm{~F} 1)$ to $6.35 \%(\mathrm{~F} 6)$. This result was expected since the sorghum and teff flours contain more fibre than rice flour. Table 1 presents the adjusted models and corresponding statistical quality parameters obtained from the experimental. Non-significant effects were excluded in the models. The significant attributes for the optimisation would be odour, and overall acceptance, the latter showing a statistically significant correlation with odour, thus explaining $72 \%$ of the data. Therefore, due to this direct correlation and the better capacity of this parameter, only the general overall acceptance model was used in the optimisation step along with the fibre content of each formulation.

The coefficients of the colour, aroma and texture models indicated that the chocolate cake formulations containing sorghum flour showed greater acceptance for such attributes, while the coefficients of the flavour and overall acceptance models showed that the cakes containing rice flour had higher acceptability regarding such sensory attributes. Also, the fibre model showed that the presence of teff flour in the formulations increases fibre content.

The contour plots of the response surfaces for colour, aroma, texture, taste, overall acceptance and fibre

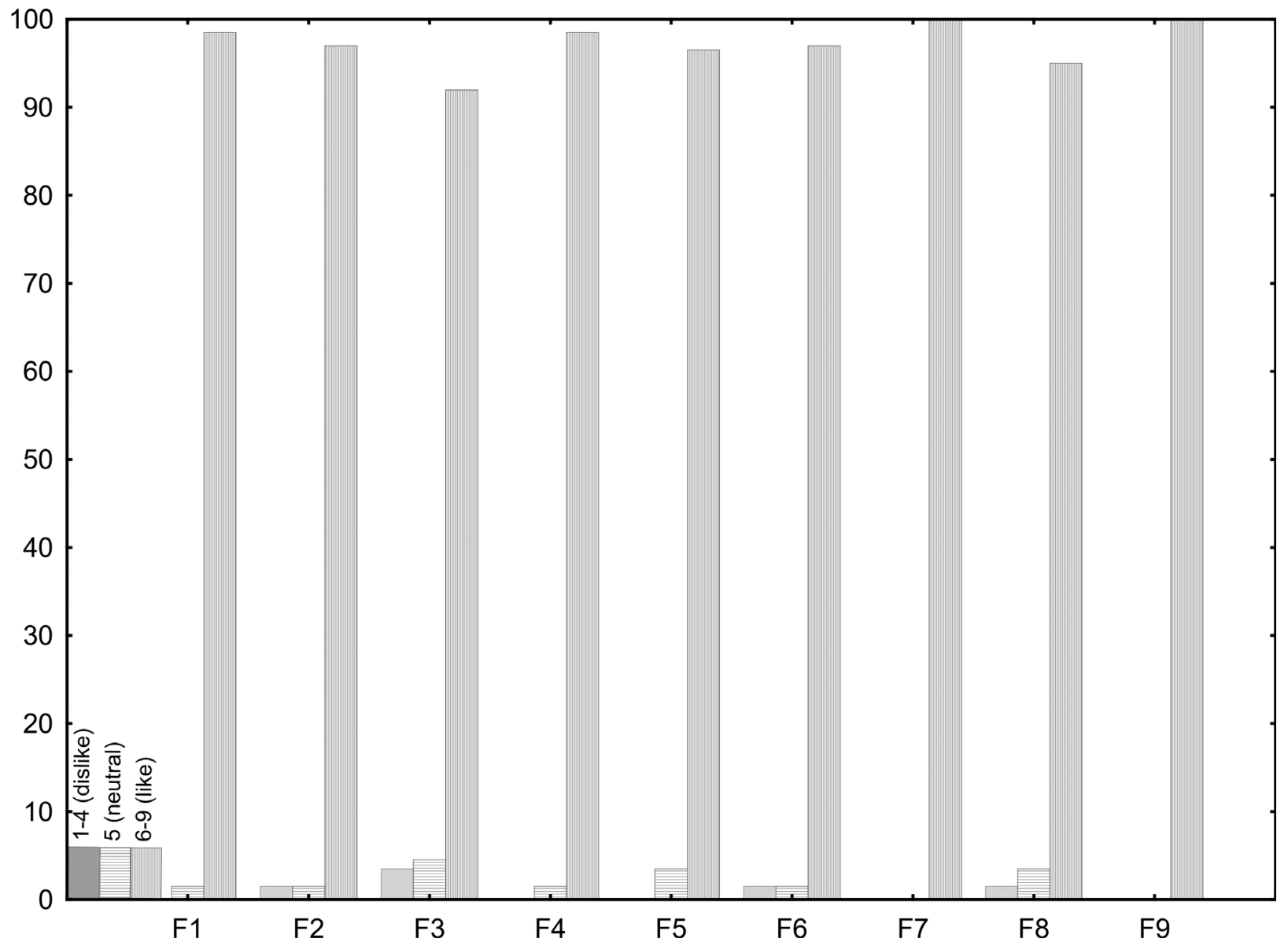

Figure 1 Overall acceptance according to classification 1-4 (dislike), 5 (neutral) and (6-9) (like) in the hedonic scale for the cake formulations. 
content with variations in the flour types and proportions in the formulations may be visualised in Fig. 2.

In the surface contour for colour, higher concentrations of teff flour combined with a little sorghum flour increase the acceptance of this attribute in the formulations, and, as rice flour is added, the approval of the colour decreases. Thus, for a better contribution to the colour aspect of the chocolate cakes, a 75:25 mixture of teff and sorghum flours increase the acceptance of the evaluated attribute.

Regarding the evaluated aroma attribute of the formulations, the response surface contour indicates that the presence of more sorghum flour increases its acceptance, including formulations using less than $50 \%$ of rice flour. Teff flour does not contribute positively to this attribute, given that, as its proportion increases in the formulations, the aroma scores decrease.

The graph for the texture attribute indicates that the sorghum flour contributes the most to its acceptance, but rice flour still contributes to a pleasant texture, as well as a 75:25 combination of sorghum and teff flour.

As can be observed on the response surface contour, formulations containing $100 \%$ of either rice or sorghum flour showed greater acceptance in the flavour attribute, and even mixtures of 75:25 rice and teff flour or of sorghum and teff flour still maintained good approval for this attribute.

In the fibre surface contour, one may notice that more expressive amounts of teff flour provide an increase in the fibre content of the cakes, which decreases with the addition of rice flour. Thus, a 50:50 mixture of teff and sorghum flours yields a formulation with higher fibre content. It may be observed in the overall acceptance surface contour that the higher the sorghum flour content in the formulations is, the better the overall acceptance of the cakes is, unlike for teff flour, whose concentration increase in the formulations causes a decrease in the overall acceptance. Through the overall acceptance response surface contour, a 50:50 blend of rice and sorghum flours, and even proportions below $25 \%$ of teff flour, generate a more significant overall acceptance for the formulations.

Figure 3 shows the desirability function, where the individual desirability values of the experimental data are shown with their minimum and maximum variations along with the overall desirability, which represents the percentages of the rice, sorghum and teff flours in the mixture for an optimal formulation. Through this function, the optimised formulation would have an estimated overall acceptance of 7.5945 and a fibre content of $5.9463 \%$, which may be observed through horizontal blue lines on the graph. The optimised formulation considered the higher amount of fibre and the best overall acceptance considering the three flours: $16.7 \%$ of rice flour, $35.8 \%$ of sorghum flour, and $47.5 \%$ of teff flour. The optimal point for each flour type may be observed through vertical red and dashed lines.

Subsequently, the optimised formulation was prepared and subjected to the overall acceptance test with 100 untrained assessors. The overall acceptance for
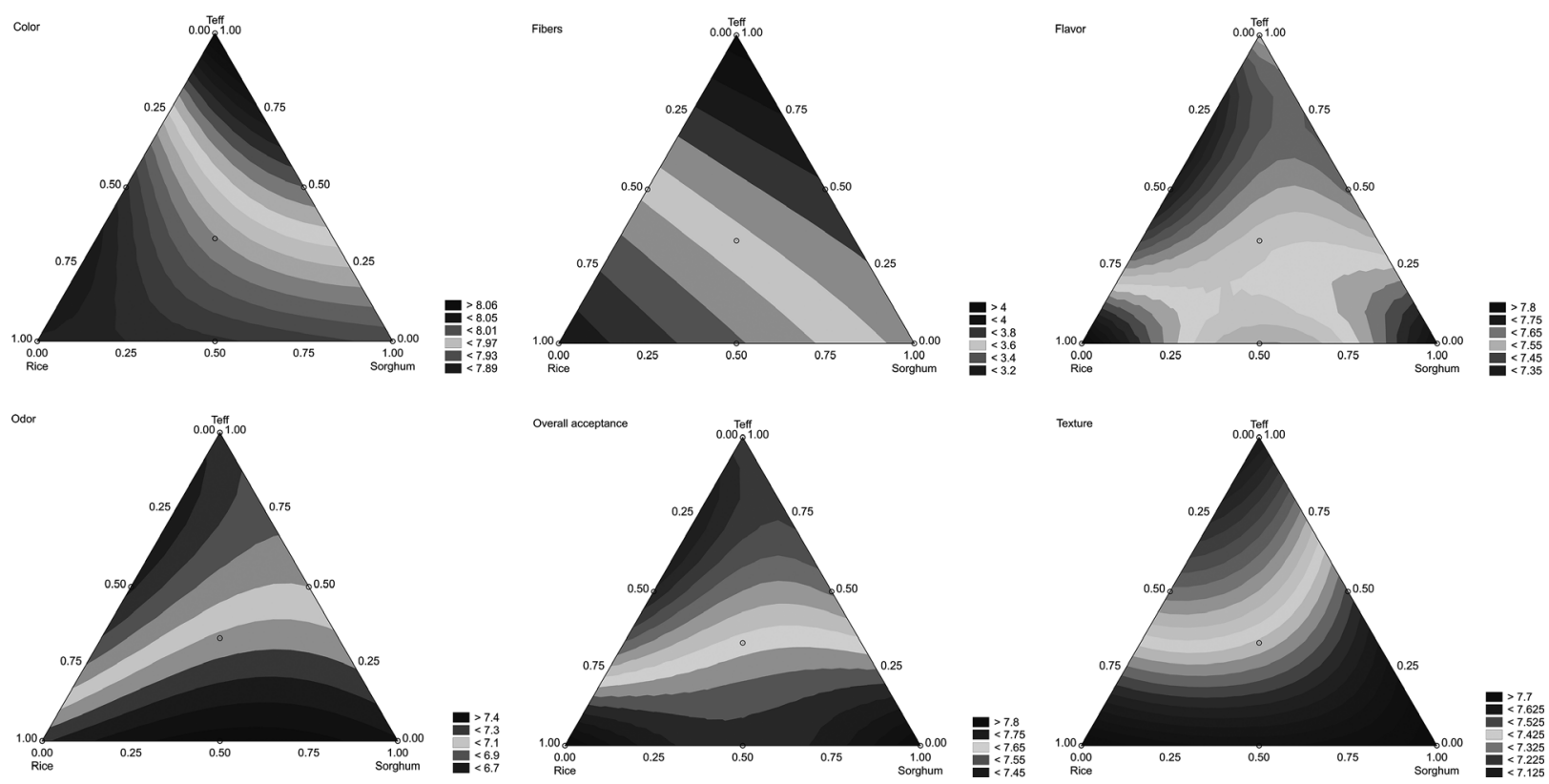

Figure 2 Contour plot of the response surfaces for colour, aroma, texture, taste, overall acceptance and fibre content. 

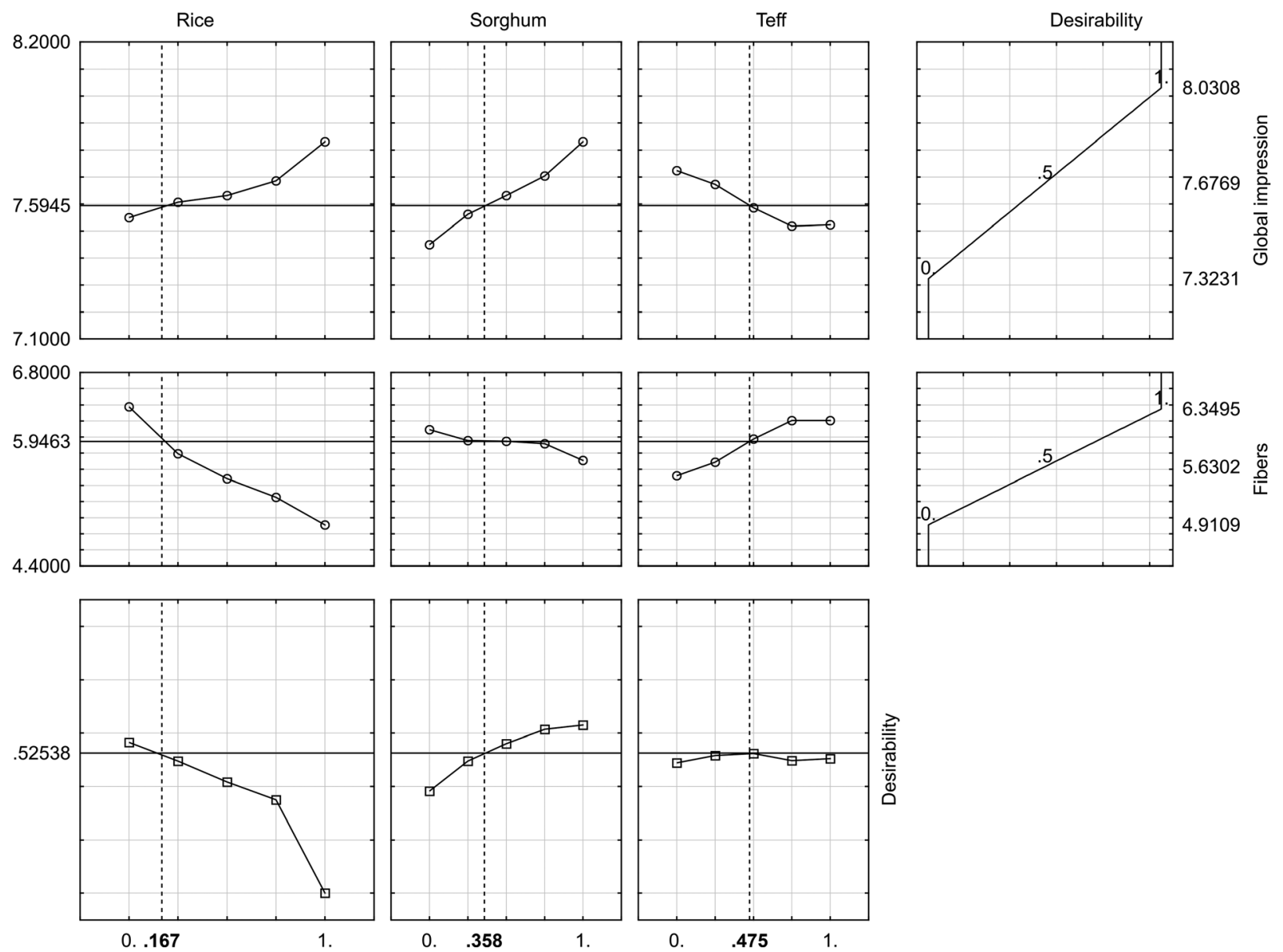

Figure 3 Graph of the desirability function.

this formulation was 7.70 , slightly higher than the value estimated by the optimisation (7.5945).

\section{Flash profile}

The panel consisted of twelve assessors (A1 to A12). Cake formulations (F1, F2, F3 and FO) were submitted to sensory descriptions through the Flash Profile, in triplicate (R1-R3). The Flash Profile ordering data were analysed by the ComDim method, and, thus, the consensus distribution of the assessors was obtained. From this output, two common dimensions (CD1 and CD2) were determined as the most important, explaining $85.3912 \%$ of the data variance, as shown in Fig. 4a.

Figure $4 \mathrm{a}$ shows that some of the formulations are well segmented and that there was reasonable reproducibility among the replicates. It is noted that F1 (rice) and F2 (sorghum) are quite distinct. Rice flour has mild sensory aspects, making it possible to make cakes without very distinctive characteristics, unlike F2, which is composed exclusively of sorghum, a type of flour with more pronounced sensory characteristics. It may also be verified that F3 (teff) and FO are more similar to each other, a fact justified by the types and concentrations of flours present in such formulations.

Figure $4 \mathrm{~b}$ shows the salience of each assessor for each common dimension, that is, the weight associated with each assessor for the formation of each common dimension. Assessor A6 is the most important for the construction of CD1, while A5 is the one that most contributes to the formation of CD2. The analysis of the salience also allows identifying the assessors who could not discriminate among the samples, that is, those that have low salience in all the most relevant common dimensions (Qannari et al., 2001), and the assessors A4 and A11 presented low salience values for both dimensions. The statistically significant correlations among the common dimensions and the attributes of the assessors are listed in Table 2. 

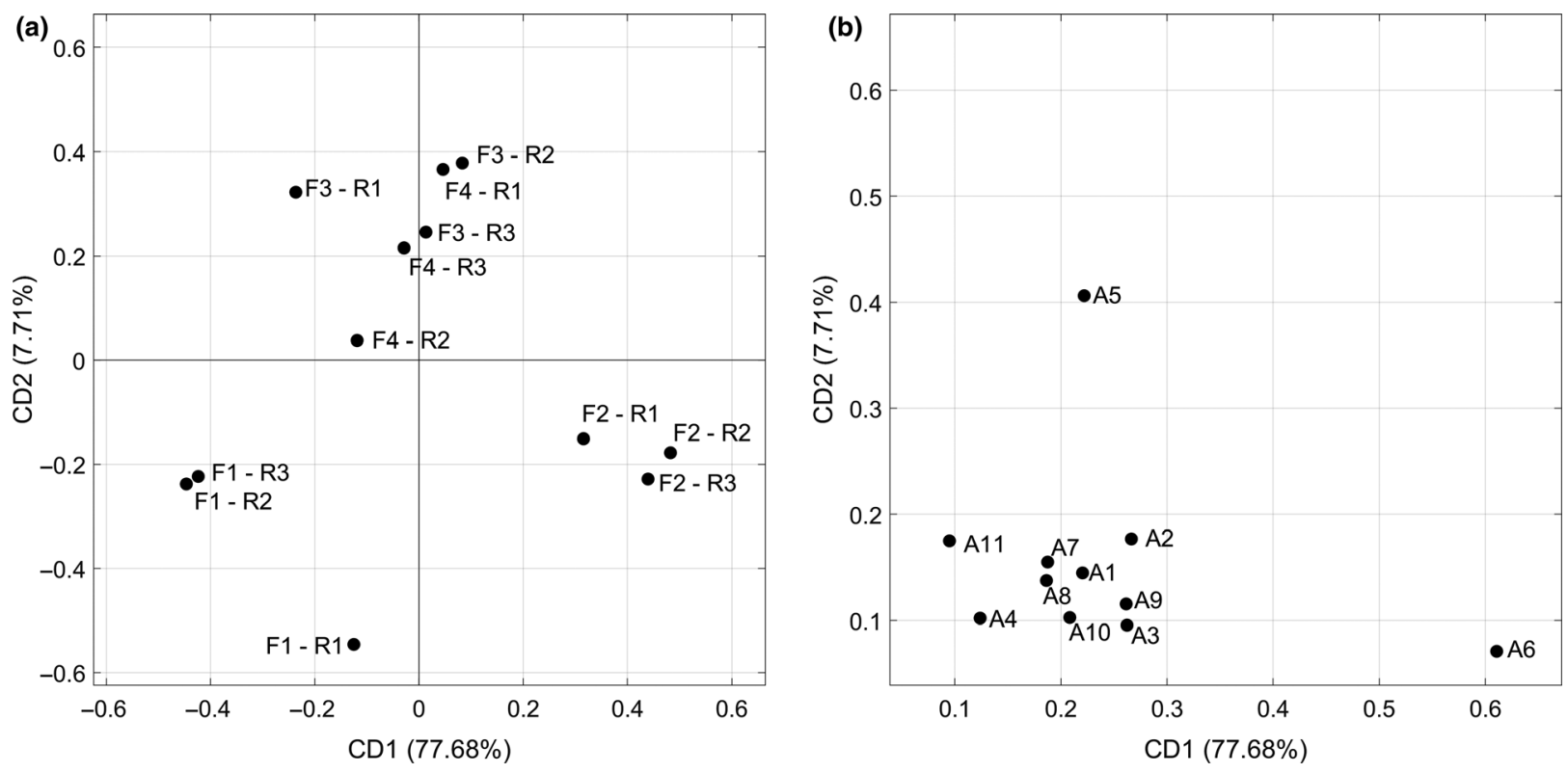

Figure 4 Graph of sample consensus (a) and assessors' salience regarding common dimensions 1 and 2 (b).

Formulation F1 (rice) is in the negative quadrants of $\mathrm{CD} 1$ and $\mathrm{CD} 2$, showing that it is a sample with a less intense brown colour, less moisture, a more intense chocolate aroma, and little brightness and elasticity. These characteristics are typical of the presence of rice flour, which has a lighter colour than the others and usually yields characteristics of lower moisture and plasticity in baking products, as well as a neutral aroma, allowing the prominence of the chocolate aroma in the formulation (Rosell \& Marco, 2008; Conte et al., 2019).

Table 2 Significant correlations $(P<0.05)$ among the common dimensions (CD) and the sensorial attributes raised in the Flash Profile

\begin{tabular}{|c|c|c|c|}
\hline \multicolumn{2}{|c|}{ Correlations with CD1 } & \multicolumn{2}{|c|}{ Correlations with CD2 } \\
\hline Negative & Positive & Negative & Positive \\
\hline $\begin{array}{l}\text { Chocolate } \\
\text { aroma (4) } \\
\text { Aerated (1) } \\
\text { Rancidity (1) } \\
\text { Flour flavour } \\
\text { (1) }\end{array}$ & $\begin{array}{l}\text { Brown Colour } \\
\text { (8) } \\
\text { Moisture (5) } \\
\text { Brightness (3) } \\
\text { Elasticity (2) } \\
\text { Aerated (1) } \\
\text { Creaminess (1) } \\
\text { Whole cereal } \\
\text { aroma (1) } \\
\text { Bitterness (1) }\end{array}$ & $\begin{array}{l}\text { Chocolate } \\
\text { flavour (3) } \\
\text { Cocoa aroma } \\
(2) \\
\text { Sweetness (1) } \\
\text { Aerated (1) } \\
\text { Yeast flavour } \\
\text { (1) }\end{array}$ & $\begin{array}{l}\text { Sweetness (2) } \\
\text { Whole cereal } \\
\text { aroma (2) } \\
\text { Chocolate } \\
\text { flavour (1) } \\
\text { Wheat flour } \\
\text { aroma (1) }\end{array}$ \\
\hline
\end{tabular}

Formulation F2 (sorghum) is in the positive quadrant of $\mathrm{CD} 1$ and negative of $\mathrm{CD} 2$, being characterised as a darker brown cake (pertaining to the darker flour), higher moisture, brightness and elasticity, as well as a less intense chocolate aroma due to the sorghum flour having a distinctive smell that masks the chocolate aroma.

Formulations F3 and FO are close to the origin of $\mathrm{CD} 1$ and in the positive quadrant of CD2. Therefore, the sweetness and the presence of a whole-grain aroma, which is related to the presence of teff flour, may be designated as attributes that characterise these formulations. Teff flour also made the whole-grain aroma attribute used to describe breads where this flour was incorporated (Viell et al., 2020). F1 and F2 have a more intense chocolate flavour than F3 and FO, suggesting that the teff flour has a very intense flavour, which, according to the assessors, decreased the taste of chocolate in the F3 and FO cakes.

Despite the substitution of rice flour for sorghum flours, teff or combinations of these in chocolate cake, promoting major changes in the sensory profile of the products, the overall acceptance among them varied little (7.52-7.83). As rice flour is removed from the cake formulations and flours of sorghum and teff are added, the product is no longer characterised as light coloured, dry, inelastic and with an intense chocolate aroma, but is characterised by a more intense brown colour, greater humidity, bright, elasticity, whole foods aroma and less intensity in chocolate aroma. This maintenance of overall acceptability despite the change 
in the product's descriptive profile is very favourable, as it suggests that consumers may be more used to and appreciate the sensory characteristics provided by whole ingredients, enjoying the health benefits that these products offer.

\section{Texture profile analysis (TPA)}

Cake formulations present significant differences for all parameters evaluated, as can be seen in Table 3 .

The highest value obtained for hardness was found for formulation F1, followed by F2, FO and F3. The same behaviour was detected for chewiness, given that the tougher the cake is, the more energy is required to break it down (Osawa et al., 2009). These results may be associated with the highest moisture content found for the FO and F3 formulations. According to Witczak et al. (2016), the exact behaviour of starch, when processed by the heat-moisture treatment, depends highly on its origin, but also on non-starch substances present in the flour which could be involved in its stabilisation, such as hydrocolloids, surfactants and other water-soluble molecules. Hager et al. (2012) reported that a lower hardness is preferred since consumers tend to associate a tough crumb with an old product. This is an advantage of the optimised formulation compared to the others, given that a reduced hardness value was found mainly due to its flour composition.

Elasticity is described by springiness and resilience, with a reduction in either one characterising a loss of elasticity (Onyango et al., 2011). F1 and FO presented the highest results for both parameters, although they are considered statistically different for the resilience parameter.

The lowest elasticity value was found for F2 sample. It is known that a batter's elasticity is related to the presence of glutenins, constituents of the gluten protein (Balakireva \& Zamyatnin, 2016). In their absence, other proteins may contribute to the elasticity of the batter. One may observe that, among the flours assessed in this study, sorghum flour is the one with the highest protein percentage (Table 3), yet this was not enough to guarantee higher springiness or resilience.

Another parameter obtained from the TPA analysis is the cohesiveness, which measures the strength of the internal bonds that define the structure of the food. In cakes, cohesiveness is the textural parameter that evaluates the rate of breakage in the mouth and easy separation on the hand (Miñarro et al., 2012). The optimised formulation presented an intermediate value when compared to the other samples, and the cake made only with rice flour (F1) showed the highest cohesiveness value.

\section{Conclusion}

The data show that it is possible to substitute rice flour, traditionally used in gluten-free products, for sorghum and teff flour in chocolate cakes, with the use of the latter increasing the fibre content of the products. The overall acceptance of the products made with the different flours practically does not change, but it was verified that the aroma is adversely affected by the addition of teff flour. Thus, the amount added of this variable must be limited.

It was possible to characterise gluten-free chocolate cake using the Flash Profile. The sample containing only rice flour showed less intense brown colour, lower moisture, brightness and elasticity, as well as a more intense chocolate aroma. The cake formulated with sorghum flour showed more intense brown colour, greater moisture, brightness and elasticity, as well as a milder chocolate aroma. The formulation made only with teff flour is similar to the optimised formulation, characterised by sweetness and a more pronounced whole-grain aroma.

The texture properties evaluated were significantly affected by the flour type, with the optimised formulation being considered the less tough and more elastic and cohesive among the samples.

It was verified that the substitution of rice flour for sorghum and teff flour did not change the overall acceptance of the cake formulations despite the great

Table 3 TPA of gluten-free cake formulations

\begin{tabular}{lccrr}
\hline & \multicolumn{2}{l}{ Formulations } & & \\
\cline { 2 - 5 } Parameters & F1 & F2 & F3 & FO \\
\hline Hardness (N) & $14.83^{\mathrm{a}} \pm 0.39$ & $13.08^{\mathrm{b}} \pm 0.30$ & $8.56^{\mathrm{d}} \pm 0.33$ & $10.20^{\mathrm{c}} \pm 0.32$ \\
Springiness (mm) & $0.92^{\mathrm{a}} \pm 0.01$ & $0.87^{\mathrm{b}} \pm 0.01$ & $0.89^{\mathrm{ab}} \pm 0.01$ & $0.89^{\mathrm{ab}} \pm 0.01$ \\
Chewiness (N.m) & $1022.38^{\mathrm{a}} \pm 16.60$ & $793.82^{\mathrm{b}} \pm 10.35$ & $494.16^{\mathrm{d}} \pm 9.70$ & $640.10^{\mathrm{c}} \pm 22.53$ \\
Cohesiveness (-) & $0.75^{\mathrm{a}} \pm 0.02$ & $0.63^{\mathrm{d}} \pm 0.01$ & $0.66^{\mathrm{c}} \pm 0.01$ & $0.69^{\mathrm{b}} \pm 0.00$ \\
Resilience (-) & $0.48^{\mathrm{a}} \pm 0.02$ & $0.35^{\mathrm{c}} \pm 0.01$ & $0.38^{\mathrm{bc}} \pm 0.01$ & $0.41^{\mathrm{b}} \pm 0.01$ \\
\hline
\end{tabular}

Means in the same line followed by different letters differ from each other according to the Tukey test $(P<0.05)$. F1: rice flour; F2: sorghum flour; F3: teff flour; FO: optimised formulation. 
change in the descriptive sensory profile of these products. This finding indicates the possibility of including healthier flours in gluten-free cakes, improving the nutritional quality of processed foods for people with celiac disease or gluten intolerance.

\section{Acknowledgments}

This work was supported by the Federal University of Technology- Paraná (UTFPR) and Araucaria Foundation. This study was financed in part by the Coordenação de Aperfeiçoamento de Pessoal de Nível Superior - Brasil (CAPES) - Finance Code 001. The authors thank the 'Central Analítica Multiusuário da UTFPR Campo Mourão' (CAMulti-CM) for the analyses.

\section{Author contributions}

Lucas Souza Nespeca: Conceptualization (equal); Data curation (equal); Formal analysis (equal); Validation (equal). Hellen Fernanda da Silva Paulino: Conceptualization (equal); Data curation (equal); Formal analysis (equal). Evandro Bona: Software (equal); Supervision (equal); Validation (equal). Fernanda Vitória Leimann: Resources (equal); Supervision (equal). Tamires Barlati Vieira da Silva: Formal analysis (equal). Flavia Reitz Cardoso: Conceptualization (equal); Supervision (equal); Validation (equal). Leila Medeiros Marques: Supervision (equal); Validation (equal). Adriana Aparecida Droval: Supervision (equal); Validation (equal). Renata Hernandez Barros Fuchs: Project administration (equal); Supervision (equal).

\section{Peer Review}

The peer review history for this article is available at https://publons.com/publon/10.1111/ijfs.14833.

\section{Data availability statement}

Research data are not shared.

\section{References}

Andersen, B.V., Brockhoff, P.B. \& Hyldig, G. (2019). The importance of liking of appearance, odour, taste and texture in the evaluation of overall liking. A comparison with the evaluation of sensory satisfaction. Food Quality and Preference, 71, 228-232.

Andrews, W., Wang, H., Jacobson, A. \& Hammack, T (2007). Laboratory Methods - BAM: Salmonella [Internet document]. FDA.

ANVISA, Agência Nacional de Vigilância Sanitária (2001). Resolução $n^{\circ}$ 12, 02 de janeiro de 2001. Regulamento Técnico sobre Padões Microbiológicos para Alimentos. [Internet document]

AOAC. (2005). Official Methods of Analysis of AOAC International. Washington, DC: Association of Official Analysis Chemists International.
Balakireva, A. \& Zamyatnin, A. (2016). Properties of gluten intolerance: gluten structure, evolution, pathogenicity and detoxification capabilities. Nutrients, 8,644 .

Barros Neto, B., Scarmino, I.S. \& Bruns, R.E. (2010). Como fazer experimentos: pesquisa e desenvolvimento na indústria.Bookman.

Campo, E., del Arco, L., Urtasun, L., Oria, R. \& Ferrer-Mairal, A. (2016). Impact of sourdough on sensory properties and consumers' preference of gluten-free breads enriched with teff flour. Journal of Cereal Science, 67, 75-82.

Capriles, V.D. \& Arêas, J.A.G. (2014). Novel Approaches in glutenfree breadmaking: interface between food science, nutrition, and health. Comprehensive Reviews in Food Science and Food Safety, 13, 871-890.

Conte, P., Fadda, C., Drabińska, N. \& Krupa-Kozak, U. (2019). Technological and nutritional challenges, and novelty in gluten-free breadmaking: a review. Polish Journal of Food and Nutrition Sciences, 69, 5-21.

Cornell, J.A. (2011). A Primer on Experiments with Mixtures. A Primer on Experiments with Mixtures, Wiley Series in Probability and Statistics. Hoboken, NJ: John Wiley \& Sons Inc.

Costantini, L., Lukšič, L., Molinari, R. et al. (2014). Development of gluten-free bread using tartary buckwheat and chia flour rich in flavonoids and omega- 3 fatty acids as ingredients. Food Chemistry, 165, 232-240.

Dairou, V. \& Sieffermann, J.-M. (2002). A comparison of 14 Jams characterized by conventional profile and a quick original method, the flash profile. Journal of Food Science, 67, 826-834.

da Silva, T.F. \& Conti-Silva, A.C. (2018). Potentiality of gluten-free chocolate cookies with added inulin/oligofructose: chemical, physical and sensory characterization. $L W T, \mathbf{9 0}, 172-179$.

FAO. (2012). Food Outlook: Global Market Analysis - November 2012. Food Outlook, Biannual Report on Grobal Food Markert.

Feng, P., Weagant, S., Grant, M. \& Burkhardt, W. (2002). Bacteriological analytical manual: enumeration of Escherichia coli and the Coliform Bacteria. In: Bacteriological Analytical Manual, 8th edn. Pp. 1-14. Washington, DC: AOAC International. https://www.fda. gov/food/laboratory-methods-food/bam-chapter-4-enumeration-esc herichia-coli-and-coliform-bacteria. Accessed on 10 October 2020

Fuchs, R.H.B., Ribeiro, R.P., Bona, E., Kitzberger, C.S.G., de Souza, C. \& Matsushita, M. (2018). Sensory characterization of Nile tilapia croquettes enriched with flaxseed flour using free-choice profiling and common components and specific weights analysis. Journal of Sensory Studies, 3333, e12324.

Gao, Y., Janes, M.E., Chaiya, B., Brennan, M.A., Brennan, C.S. \& Prinyawiwatkul, W. (2018). Gluten-free bakery and pasta products: prevalence and quality improvement. International Journal of Food Science and Technology, 53, 19-32.

Giménez-Bastida, J.A., Piskuøa, M. \& Zieliński, H. (2015). Recent advances in development of gluten-free buckwheat products. Trends in Food Science and Technology, 44, 58-65.

Hager, A.S., Wolter, A., Czerny, M. et al. (2012). Investigation of product quality, sensory profile and ultrastructure of breads made from a range of commercial gluten-free flours compared to their wheat counterparts. European Food Research and Technology, 235, 333-344.

ISO-8586:2012 (2012). General guidelines for the selection, training and monitoring of selected assessors and expert sensory assessors. International Organization for Standardization, 1-28.

Jouan-Rimbaud Bouveresse, D., Pinto, R.C., Schmidtke, L.M., Locquet, N. \& Rutledge, D.N. (2011). Identification of significant factors by an extension of ANOVA-PCA based on multi-block analysis. Chemometrics and Intelligent Laboratory Systems, 106, 173-182.

Korus, J., Witczak, T., Ziobro, R. \& Juszczak, L. (2015). Linseed (Linum usitatissimum L.) mucilage as a novel structure forming agent in gluten-free bread. LWT - Food Science and Technology, 62, 257-264. 
Krupa-Kozak, U., Wronkowska, M. \& Soral-Śmietana, M. (2011). Effect of buckwheat flour on microelements and proteins contents in gluten-free bread. Czech Journal of Food Sciences, 29, 103-108.

Lebwohl, B., Sanders, D.S. \& Green, P.H.R. (2018). Coeliac disease. The Lancet, 391, 70-81.

Marston, K., Khouryieh, H. \& Aramouni, F. (2016). Effect of heat treatment of sorghum flour on the functional properties of glutenfree bread and cake. LWT - Food Science and Technology, 65, 637644

Marti, A., Marengo, M., Bonomi, F. et al. (2017). Molecular features of fermented teff flour relate to its suitability for the production of enriched gluten-free bread. $L W T, \mathbf{7 8}, 296-302$.

McCann, T., Krause, D. \& Sanguansri, P. (2015). Sorghum - New gluten-free ingredient and applications. Food Australia, 67, 24-26.

Miñarro, B., Albanell, E., Aguilar, N., Guamis, B. \& Capellas, M. (2012). Effect of legume flours on baking characteristics of glutenfree bread. Journal of Cereal Science, 56, 476-481.

Mohammed, M.I.O., Mustafa, A.I. \& Osman, G.A.M. (2009). Evaluation of wheat breads supplemented with teff (Eragrostis tef (zucc.) trotter) grain flour. Australian Journal of Crop Science, 3, $207-212$.

Moscatto, J.A., Prudêncio-Ferreira, S.H. \& Hauly, M.C.O. (2004). Farinha de yacon e inulina como ingredientes na formulação de bolo de chocolate. Ciência e Tecnologia de Alimentos, 24, 634-640.

Onyango, C., Mutungi, C., Unbehend, G. \& Lindhauer, M.G (2011). Modification of gluten-free sorghum batter and bread using maize, potato, cassava or rice starch. LWT - Food Science and Technology, 44, 681-686.

Osawa, C.C., Fontes, L.C.B., Miranda, E.H.W., Chang, Y.K. \& Steel, C.J. (2009). Avaliação físico-química de bolo de chocolate com coberturas comestíveis à base de gelatina, ácido esteárico, amido modificado ou cera de carnaúba. Ciência e Tecnologia de Alimentos, 29, 92-99.

Qannari, E.M., Courcoux, P. \& Vigneau, E. (2001). Common components and specific weights analysis performed on preference data. Food Quality and Preference, 12, 365-368.

Rosell, C.M., Barro, F., Sousa, C. \& Mena, M.C. (2014). Cereals for developing gluten-free products and analytical tools for gluten detection. Journal of Cereal Science, 59, 354-364.

Rosell, C.M. \& Marco, C. (2008). Rice. In: Gluten-Free Cereal Products and Beverages (edited by E.K. Arendt \& F. dal Bello). Pp. 81I00. London, UK: Elsevier Science.
Sakač, M., Pestorić, M., Mišan, A. et al. (2015). Antioxidant capacity, mineral content and sensory properties of gluten-free rice and buckwheat cookies. Food Technology and Biotechnology, 53, 38-47.

Salehi, F. (2019). Improvement of gluten-free bread and cake properties using natural hydrocolloids: a review. Food Science and Nutrition, 7, 3391-3402.

Steffolani, E., de la Hera, E., Pérez, G. \& Gómez, M. (2014) Effect of Chia (Salvia hispanica L.) addition on the quality of gluten-free bread. Journal of Food Quality, 37, 309-317.

Stone, H. \& Sidel, J.L. (2004). Sensory Evaluation Practices. Sensory Evaluation Practices, 3rd edn. Redwood City, CA: Elsevier.

Torbica, A., Hadnađev, M. \& Dapčević Hadnađev, T. (2012). Rice and buckwheat flour characterisation and its relation to cookie quality. Food Research International, 48, 277-283.

Turkut, G.M., Cakmak, H., Kumcuoglu, S. \& Tavman, S. (2016) Effect of quinoa flour on gluten-free bread batter rheology and bread quality. Journal of Cereal Science, 69, 174-181.

USDA. (2015). National Nutrient Database for Standard Reference, Release28 [WWW Document]. U.S. Department of Agriculture, Agricultural Research Service. http://www.ars.usda.gov/nutrientda ta. Accessed on 10 October 2020

Vad Andersen, B. \& Hyldig, G. (2015). Food satisfaction: integrating feelings before, during and after food intake. Food Quality and Preference, 43, 126-134.

Viell, F.L.G., Tonon, G.C., Perinoto, L.C. et al. (2020). Sensory characterization of gluten-free bread enriched with teff (Eragrostis tef (Zucc.) Trotter) and yacon (Smallanthus sonchifolius) using flash profile and common dimension analysis. Journal of Food Processing and Preservation, 44, e14335.

Witczak, M., Ziobro, R., Juszczak, L. \& Korus, J. (2016). Starch and starch derivatives in gluten-free systems - A review. Journal of Cereal Science, 67, 46-57.

Zhu, F. (2018). Chemical composition and food uses of teff (Eragrostis tef). Food Chemistry, 239, 402-415.

\section{Supporting Information}

Additional Supporting Information may be found in the online version of this article:

Figure S1. Cakes related to formulations F1, F2, F3 and $\mathrm{FO}$. 